3 Research Square

\title{
Au-Ag Binary Alloys on n-GaAs Substrates and Effect of Work Functions on Schottky Barrier Height
}

\author{
Abdullah AKKAYA ( $\square$ abdullah.akkaya@ahievran.edu.tr) \\ Ahi Evran University https://orcid.org/0000-0002-4086-6365
}

\section{Research Article}

Keywords: Gold-silver alloy, electrical transport, leakage current, Fermi level pinning, density of interface states

Posted Date: February 23rd, 2021

DOl: https://doi.org/10.21203/rs.3.rs-226316/v1

License: (9) This work is licensed under a Creative Commons Attribution 4.0 International License. Read Full License 


\title{
Au-Ag Binary Alloys on n-GaAs Substrates and Effect of Work Functions on Schottky Barrier Height
}

\author{
Abdullah Akkaya \\ Department of Chemistry and Chemical Processing Technologies, Mucur Vocational School, \\ Kırşehir Ahi Evran University, Kırşehir, Turkey
}

\begin{abstract}
In this study, I investigated the effect of work function $\left(\phi_{m}\right)$ of $\operatorname{Au}_{\mathrm{x}} \mathrm{Ag}_{1-\mathrm{x}}(\mathrm{x}=0,0.22,0.37,0.71$ and 1) on the $A u-A g / n-G a A s$ Schottky diode (SD) parameters. Ag, Au and three alloys with different compositions deposited on $\mathrm{n}-\mathrm{GaAs}$ substrates by thermal evaporation method. Surface morphologies of the samples were investigated by atomic force microscope (AFM). Elementel compositions of Schottky metals were conducted by the energy dispersive X-ray spectroscop (EDX). Current-voltage (I-V) and capacitance-voltage (C-V) measurements performed at room temperature.

SD parameters such as barrier height $\left(\Phi_{\mathrm{b} 0}\right)$, ideality factor $(\mathrm{n})$, series resistance $\left(R_{\mathrm{S}}\right)$, and interface state density $\left(D_{\text {it }}\right)$ of the SD's were calculated from the obtained I-V and C-V data. Experimental results showed that all calculated SD parameters depends on alloy composition. Lowest mean barrier height value was found as $0.789 \pm 0.022 \mathrm{eV}$ for $A u / n-G a A s$ SDs and the highest value was determined $0.847 \pm 0.008 \mathrm{eV}$ for $A u_{0.71} \mathrm{Ag}_{0.29} / n-G a A s$ SDs from I-V measurements. Weak dependencies of barrier height to $\phi_{m}$ was exist and gap state parameter (S) determined as 0.0526. S value was close to the Bardeen limit $(S=0)$, and indicates that Fermi level was strongly pinned in $A u-A g / n-G a A s$ SDs. Also, main SD parameters like series resistance $\left(R_{\mathrm{S}}\right)$, ideality factor $(n)$, reverse bias barrier height $\left(\Phi_{b}{ }^{R B}\right)$, doping density $\left(N_{d}\right)$ and density of interface states $\left(D_{\text {it }}\right)$ were calculated via using different methods from I-V and C-V measurement results. In addition, to determine the leakage current mechanism Poole-Frenkel emission (PFE) and Schottky emission (SE) models applied on reverse bias I-V data.
\end{abstract}

\section{Keywords}

Gold-silver alloy; electrical transport; leakage current, Fermi level pinning; density of interface states. 


\section{Introduction}

Barrier formation mechanisms of metal-semiconductor contacts have been a major research topic since the first discovery of these contacts [1-4]. In order to accurately identify the current flowing through the contact and determine the operating conditions of the devices, the basic parameter, barrier height $\left(\Phi_{b}\right)$, have to be defined correctly. First attempt was realized by Schottky to understand the rectifying behavior of metal-semiconductor contacts [5]. Schottky and Mott subsequently proposed a model for barrier formation and calculating the barrier height [5-7]. According to the Schottky-Mott rule [7], under the ideal condition, the factors affecting this barrier height was an electron affinity of the semiconductor $\left(\chi_{s}\right)$ and the work function of metal $\left(\phi_{m}\right)$, and it was simply expressed as follows;

$$
\Phi_{b}=\phi_{m}-\chi_{s}
$$

Since Schottky-Mott rule is almost never verified experimentally, it can be concluded that; interface dipoles do not disappear and play a major role in determining the properties of the metal-semiconductor interface [8]. The $\phi_{m}$ value of the metal depends on two components; volume term and surface dipole term, which starts just below the surface of the metal and represents where all bulk properties are same. Both dipole terms strongly correlate with surface charge distribution and depend on the condition of the surface [9]. Moreover, it was commonly known that, when a metal and semiconductor are brought into a contact without any interface layer, the atomic sites and charge distributions change, so that the contribution of the surface dipole changes. Louie et al. to overcome this situation, used the metal's electronegativity instead of the function of the metal [10]. In addition, in the presence of states at the interface has a significant effect on the formation of barrier height and investigated in many studies $[2,7,8$, 11-15].

Although Schottky-Mott rule provides accurate estimation of band bending in a semiconductor, the validity of the proposed model, due to the presence of states at the interface between the metal and the semiconductor and the "Fermi level pinning" caused by these finite states, is a matter of discussion especially for some semiconductors $[2,16]$. According to this model, if the thin insulating layer exists between a semiconductor and a metal, interface states of semiconductor are occupied by the electrons, create additional space charge region, and create potential difference. This potential difference reduces the effect of metals work function on barrier height [16]. Experimentally observed barrier height has a very limited relation to the results of this theory $[8,14,17]$. Few models proposed to reveal the formation of barrier height in a metal semiconductor contact $[2,11,18]$. Some of these models associate the independence of the barrier height from the $\phi_{m}$ with the fermi level pining mechanism caused by high density interface states [2]. Some other models are closely interested in interfacial chemistry and address the interaction of interfacial dipole with bond polarization [11]. However, all proposed models haven't yet emerged to explain the properties of metal-semiconductor contacts precisely, are not complete and usually changes with the substrate, metal, substrate cleaning method, metal deposition method, etc. [9]. It is possible to determine the diode parameters (tuning) during the production of diodes to serve a specific purpose. It is sufficient to use metals or semiconductors with different work functions $[9,13,19,20]$. 
GaAs has high thermal strength, high electron mobility and high resistance to radiation damage. It also has a direct band gap that allows efficient absorption of light emission and absorption, allowing transistors to operate at very high frequencies, reducing the noise at which higher frequencies tend to reduce electrical signal distortion in electronic circuits. Also, ternary and quaternary alloys created from GaAs utilizing elements like Al, In, P, and SB have properties that complement those of GaAs, which allows adaptability. GaAs is an important substrate material for devices, which its used in both in micro- and opto-electronic applications. Also, GaAs is a suitable substrate for a basic components for high speed and low power electronics. On the condition that the properties of the semiconductor remain the same (assuming the effect of interface states to be invariant), modifications in the composition of Schottky metal should be expected to change the barrier height. Both of $\mathrm{Au}$ and $\mathrm{Ag}$ have very similar properties such as conductivity, molar heat capacity, crystal structure, atomic and covalent radius. They miscible in all portions and known as good contact properties with GaAs.

In this study, the effect of modification in the $\phi_{m}$ of Schottky metal was investigated by the depending on the composition of alloys. For this purpose, electrical measurements (currentvoltage and capacitance-voltage) were performed at room temperature on produced 20 Schottky barrier diodes (SDs) which it was fabricated by using two metals (Ag, Au) and three different alloys on $\mathrm{n}-\mathrm{GaAs}$. The characteristic parameters of SDs such as ideality factor $(n)$, barrier height $\left(\Phi_{b}\right)$, series resistance $\left(R_{s}\right)$, reverse bias barrier height $\left(\Phi_{b}{ }^{R B}\right)$ etc. have been determined and compared with each other. Pinning position of the Fermi level and density of interface states $\left(D_{i t}\right)$ have been determined and the validity of the Schottky-Mott rule for the Au-Ag/GaAs was tested.

The n-type GaAs substrate used in this study was grown by the LEC method and Te-doped with a carrier concentration of $2-5 \times 10^{17} \mathrm{~cm}^{3}$. To remove organic contaminations on GaAs substrate, it was cleaned with some solvents (acetone, methanol, trichloroethylene, deionized water) 5 min using ultrasonic agitation in each step. Then, GaAs substrate was immersed in an $\mathrm{HCl}: \mathrm{H}_{2} \mathrm{O}(1: 1)$ etching solution to eliminate the thin native oxide layer on the surface, rinsed with de-ionized water (18 M $\Omega$ ) and high purity nitrogen gas used for drying. After the etching process, GaAs substrate inserted into the metal deposition chamber immediately.

The Ohmic contacts and transfer length method (TLM) patterns were built by thermal evaporation of Au-Ge alloy (wt.\% 12), on non-polished side of substrate with a thickness of $200 \mathrm{~nm}$, at $2 \times 10^{-6}$ Torr base chamber pressure and thermally annealed at $350{ }^{\circ} \mathrm{C}$ for $2 \mathrm{~min}$. in flowing high purity $(5 \mathrm{~N})$ nitrogen gas in a tube furnace. TLM method [21] was used to characterize the electrical contacts, with gaps of $0.25,0.50,0.75 \mathrm{~mm}$ between $0.7 \times 3.5 \mathrm{~mm}$ pads. Specific contact resistance $\left(\rho_{c}\right)$, contact resistance $\left(R_{c}\right)$, and the effective length $\left(L_{e f f}\right)$ derived from the measured $I-V$ data and the calculated total resistance versus gap spacing by TLM and values was $9.899 \times 10^{-6} \Omega \mathrm{cm}^{2}, 0.510 \Omega \mathrm{cm}$ and $0.770 \mu \mathrm{m}$, respectively.

The substrate divided into 5 parts and the area of each part was approximately $1 \mathrm{~cm}^{2}$. Each part immediately inserted into the vacuum chamber of NVTS-400 to form Schottky contacts by thermal evaporation of metals and alloys. The $\mathrm{Au}_{\mathrm{x}} \mathrm{Ag}_{1-\mathrm{x}}$ alloys made at tungsten crucibles, using a high purity $\mathrm{Au}(4 \mathrm{~N} 5)$ and $\mathrm{Ag}(5 \mathrm{~N})$ parts, repeating the melt-cooling cycle at least five times 
and under vacuum. Alloy composition ( $\mathrm{x}=0,0.22,0.37,0.71$ and 1$)$ was verified by $E D X$ measurements and given in Table 1. Schottky contact metals/alloys thermally evaporated through a tungsten shadow mask on the front side of the wafers with diode area was $0.785 \mathrm{~mm}^{2}$. Electrical characteristics of $A u-A g / n-G a A s$ SDs studied from dc current-voltage $(I-V)$ measurements (measured with the HP4140B picoammeter) and frequency dependent capacitance-voltage $(C-V)$ measurements (measured with Agilent E4980A LCR meter) in the dark and $300 \mathrm{~K}$. The forward and reverse bias $I-V$ measurements evaluated using the standard thermionic emission theory, and Poole-Frenkel and Schottky emission theory. $C-V$ measurement results were also evaluated using diode capacitance, and single frequency approximation for interface state density distribution model. All measurements and calculations performed with our SeCLaS-PC program [22, 23].

\section{Results and Discussion}

\subsection{Work functions and surface morphology of binary Au-Ag alloy}

The work function was one of the most basic properties of material surfaces and it is directly affects electrical properties of metal-semiconductor contacts. Although the work functions of metals are well documented for various elements, information about the work functions of alloy surfaces and its dependence on composition is limited [24]. Segregation, especially in alloys, makes it difficult to determination of work functions of the alloys [25]. Generally, Gelatt and Ehrenreich's model is used for determine the work function of the alloy [31-34] in the experimental studies. According to this method, the work function of an alloy in the form of $\mathrm{A}_{\mathrm{x}} \mathrm{B}_{1-\mathrm{x}}$ was,

$$
\phi_{m}=x \phi_{m, A}+(1-x) \phi_{m, B}+x(1-x)\left[\frac{\left(\phi_{m, A}-\phi_{m, B}\right)\left(\rho_{A} / \rho_{b}\right)-1}{x\left(\rho_{A} / \rho_{b}\right)+(1-x)}\right]
$$

where $\rho_{A}$ and $\rho_{B}$ are total densities of states $\phi_{m, A}$ and $\phi_{m, B}$ are the work functions, and of metal $\mathrm{A}$ and $\mathrm{B}$, respectively. The density of states at Fermi level depends on electronic specific heat constant $C_{e}=(1 / 3) \pi^{2} \rho k^{2} T$. $C_{e}$ values of $\mathrm{Au}$ and $\mathrm{Ag}$ are 0.948 and $0.645 \mathrm{mJmol}^{-1} \mathrm{~K}^{-2}$, respectively [26]. Contrary to the model proposed by Fain et al. [31], since this electronic specific heat constant values was not close to each other, so work functions could not show a linear variation. When the work functions considered as $5.22 \mathrm{eV}$ and $4.30 \mathrm{eV}$ for $\mathrm{Au}$ and $\mathrm{Ag}$ [34], respectively, obtained work functions of alloys was given in Table 1 with the corresponding atomic composition.

Grain size of Schottky metals and condition of the surface of this metal/alloy plays an important role in determining the electrical properties [27, 28]. Atomic force microscopy was used to examine the surface morphology of the Au-Ag Schottky contacts on n-GaAs. Figure 1 shows the $A F M$ images of the $A u / n-G a A s$ and $A g / n-G a A s$ SDs. As shown in Figure, surface morphology of the SDs was fairly smooth. Root mean square (RMS) roughness of films was found from 20x20 $\mu \mathrm{m}$ image area and values was $45.9 \mathrm{~nm}$ for $\mathrm{Au}, 37.8 \mathrm{~nm}$ for $\mathrm{Au}_{0.71} \mathrm{Ag}_{0.29}, 46.2 \mathrm{~nm}$ for $\mathrm{Au}_{0.37} \mathrm{Ag}_{0.63}, 29.5 \mathrm{~nm}$ for $\mathrm{Au}_{0.22} \mathrm{Ag}_{0.78}$ and $26.1 \mathrm{~nm}$ for $\mathrm{Ag}$. Correlation was not observed between the RMS values of the alloys and metals. However, relatively high RMS values are the result of the island-type metallization process observed 
during the metallization process [29-31]. The phenomenon of island formation of metals is typically observed between low and high surface energy materials. In order to minimize the total surface energy of the system, the metals/alloys agglomerates to minimize its surface area and exposes more surface area of the low surface energy materials (surface energies were determined as $0.86 \mathrm{~J} / \mathrm{m}^{2}, 1.51 \mathrm{~J} / \mathrm{m}^{2}$ and $1.97 \mathrm{~J} / \mathrm{m}^{2}$ for GaAs, $\mathrm{Ag}$ and Au, respectively) [32].

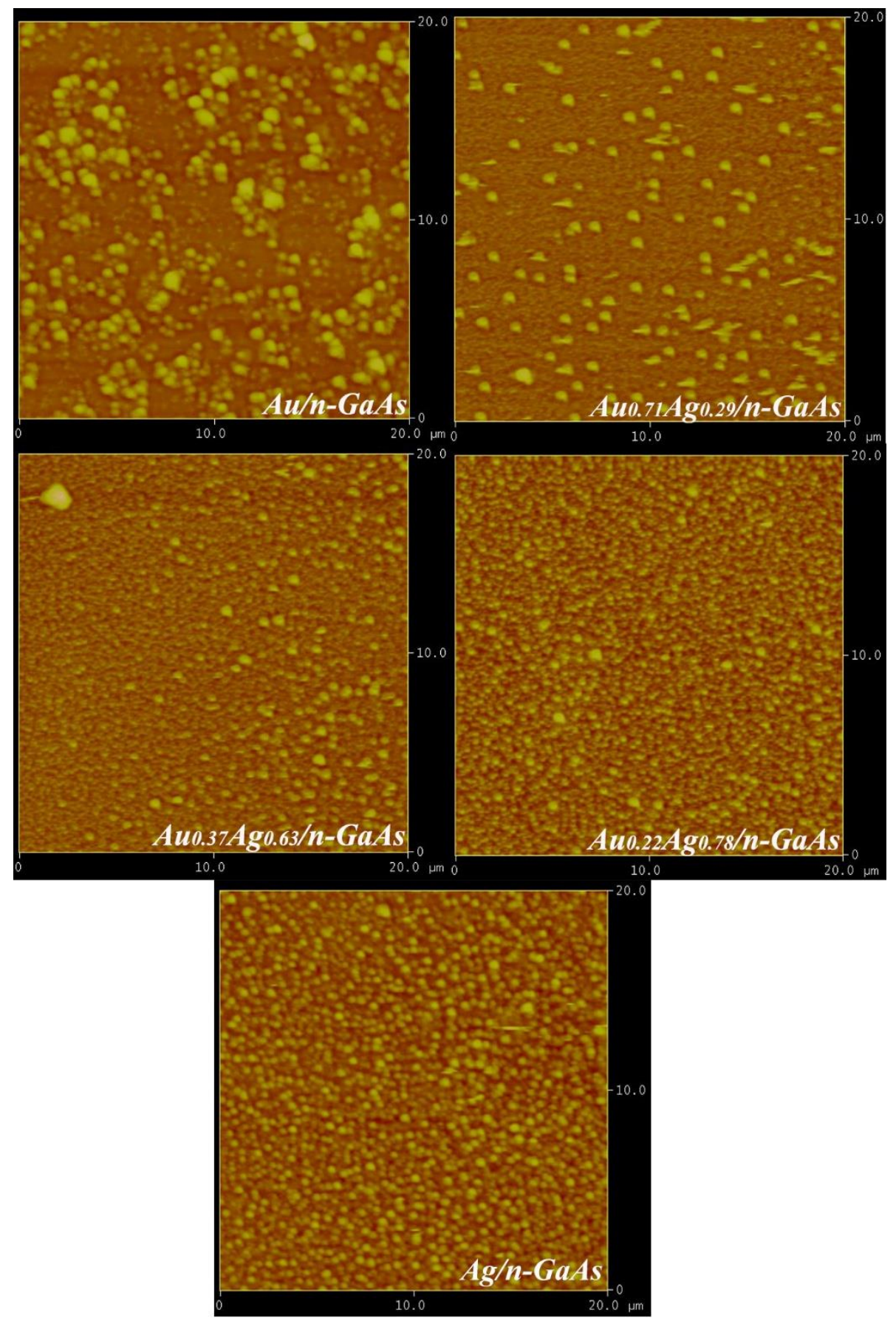

Figure 1. AFM micrographs of the Au-Ag Schottky contacts to n-type GaAs.

\subsection{Forward bias $I-V$ characteristics of the $A u-A g / n-G a A s$ SDs}

The semi-logarithmic forward and reverse $I-V$ characteristics of one $A u-A g / n-G a A s$ SDs shown in Figure 2. As can be seen in Figure 2, the rectifying properties of the SD depend on 
the alloy composition and therefore they depend on the work function. These experimental plots analyzed by using thermionic emission theory, assuming the barrier was homogeneous. According to the theory, the flowing current through the diode in the forward bias region (for $\mathrm{V} \geq 3 \mathrm{kT} / \mathrm{q})$ is as follows [7, 33];

$$
I=I_{0} e^{q V / n k T}
$$

and

$$
I_{0}=A A^{*} T^{2} e^{-q \Phi_{b}^{I V} / k T}
$$

where $I_{0}, V, n, k, T, A^{*}, A, q$, and $\Phi_{b}{ }^{I V}$ are the saturation current at zero bias, the applied bias voltage, the ideality factor, the Boltzmann constant, the temperature in Kelvin, the effective Richardson constant $\left(8.16 \mathrm{Acm}^{-2} \mathrm{~K}^{-2}\right.$ for $\left.\mathrm{n}-\mathrm{GaAs}\right)$, the effective diode area, the electron charge, and the barrier height, respectively.

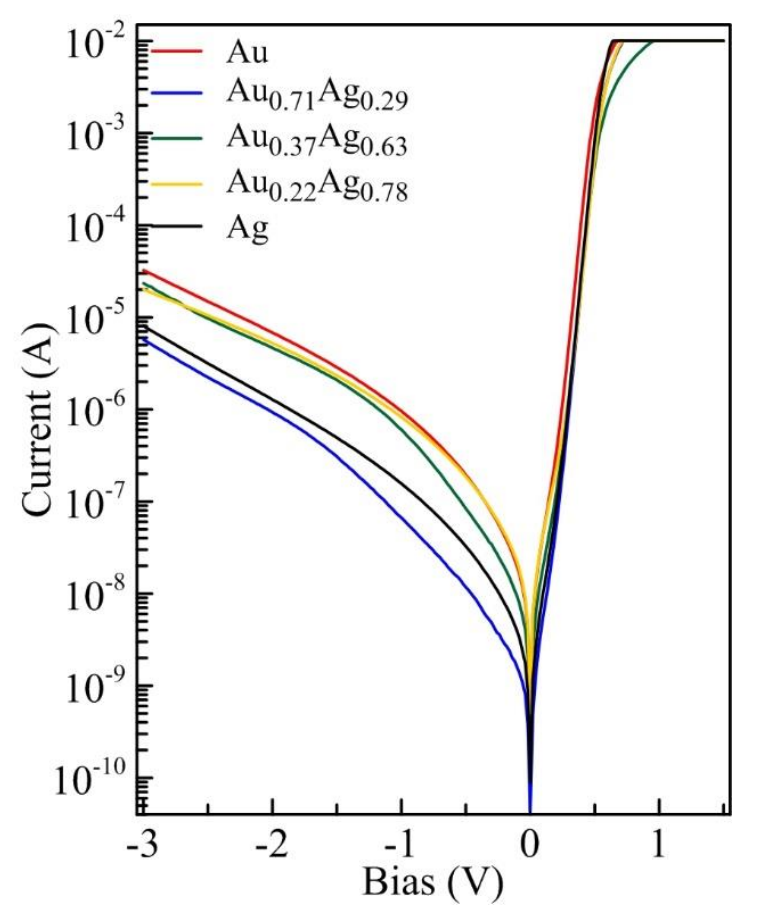

Figure 2. The semi-logarithmic $I-V$ characteristics for the $A u-A g / n-G a A s$ SDs. Only one plot shown here for each set, representing the best value for the average results obtained from the measurements.

In Equation (4), $n$ is a dimensionless parameter and its indicator for the deviation from the theory (ideally equals unity). The experimental values of the $n$ and the $\Phi_{b}$ were determined from slopes and intercepts of the linear regions of the forward bias $\ln I-V$ plots by using Equations (3 and 4). Other calculations and all least square fittings performed via our computer program SeCLaS-PC. The values of the $\Phi_{b}$ and $n$ of the $A u-A g / n-G a A s$ SD varied with alloy compositions (Table 1). As can be seen in Table 1, the ideality factors of $A u-A g / n-G a A s$ SDs were higher than the 1 . This high value of the ideality factors was generally attributed to an existence of a thin oxide layer between metal and semiconductor, surface preparation techniques, Fermi level pinning, and homogeneity of the surface of the semiconductor [28, 34]. 
Ideally, when the metal and semiconductor are combined to form a contact, the boundary between the metal and the semiconductor is assumed sharp, but in real situation is different. As stated in previous studies, even if the metallization process carried out at room temperature, solid-state reactions occur between the metal and the semiconductor [29, 31, 34-36]. This was more clearly seen in $A u / G a A s$ SDs. Gallide phases formed at the interface was known and have a significant effect on both the $n$ and the $\Phi_{b}{ }^{I V}[35,37]$. In this study, similar results were obtained for $n$ and the $\Phi_{b}{ }^{I V}$ and these values vary depending on the contact metal/alloy. The ideality factor of the alloys decreases when the amount of silver increases. The possible reason for this change may be silver prevents the formation of the gallide phases.

It was a well-known method to incorporate very thin barrier metal films in order to allow metals of such diffusive nature to make better contact with semiconductors or to achieve diffusion in a controlled manner.

Table 1. Composition, work function, characteristics diode parameters and standard deviations of the $A u-A g / n-G a A s$ SDs.

\begin{tabular}{|c|c|c|c|c|c|c|c|}
\hline \multirow{2}{*}{ Sample } & \multicolumn{2}{|c|}{ Ag } & \multicolumn{2}{|c|}{$\mathbf{A u}$} & \multirow{2}{*}{$\phi_{m}(\mathbf{e V})$} & \multirow{2}{*}{$n$} & \multirow{2}{*}{$\Phi_{b}^{(I V)}(\mathrm{eV})$} \\
\hline & (wt.\%) & (at.\%) & (wt.\%) & (at.\%) & & & \\
\hline $\mathbf{A u}$ & 0.0 & 0.0 & 100.0 & 100.0 & $5.22[38]$ & $1.171 \pm 0.022$ & $0.789 \pm 0.022$ \\
\hline Au0.71Ag0.29 & 18.28 & 29.00 & 81.72 & 71.00 & 5.07 & $1.158 \pm 0.019$ & $0.847 \pm 0.008$ \\
\hline $\mathrm{Au}_{0.37 \mathrm{Ag}_{0.63}}$ & 51.23 & 63.48 & 48.77 & 36.52 & 4.96 & $1.188 \pm 0.022$ & $0.832 \pm 0.004$ \\
\hline Au0.22Ag0.78 & 66.32 & 78.24 & 33.68 & 21.76 & 4.65 & $1.238 \pm 0.022$ & $0.825 \pm 0.010$ \\
\hline Ag & 100.0 & 100.0 & 0.0 & 0.0 & $4.30[38]$ & $1.255 \pm 0.027$ & $0.802 \pm 0.006$ \\
\hline
\end{tabular}

The obtained mean value of barrier height and ideality factor for twenty $A u / n-G a A s$ SDs was $0.789 \pm 0.022 \mathrm{eV}$ and $1.171 \pm 0.022$, respectively. These values are considerably lower than the expected barrier height value. However, many studies have obtained different values for the barrier height of these SDs [20, 39-44]. For example; Tunhuma et al. found these values $0.85 \mathrm{eV}$ and 1.10 for $A u / n-G a A s$ SDs at room temperature [41]. Özdemir et al. found these values $0.742 \mathrm{eV}$ and $1.247 \mathrm{and}$, Korucu et al. found that $0.79 \mathrm{eV}$ and 1.034 for $A u / n-G a A s$ SDs around the room temperature $[42,43]$.

The electrical parameters of the diodes depend on the method of cleaning of the substrates [45], the metallization method [46], the etching method [47] etc. Tsukamato et al. worked on photocatalytic properties of alloy $(\mathrm{Au}-\mathrm{Ag}) / \mathrm{TiO}_{2}$ junctions [19]. They founded that the work function of the Au-Ag alloy lies at the level intermediate between the monometallic $\mathrm{Au}$ and $\mathrm{Ag}$ and calculated theoretical energy-band diagram of alloy/ $\mathrm{TiO}_{2}$ junction. According to their results, barrier heights changes $0.2 \mathrm{eV}$ to $1.3 \mathrm{eV}$ for $\mathrm{Ag} / \mathrm{TiO}_{2}$ and $\mathrm{Au} / \mathrm{TiO}_{2}$, respectively. The alloy/ $/ \mathrm{TiO}_{2}$ junction therefore creates a barrier that is larger than $\mathrm{Ag} / \mathrm{TiO}_{2}$ but smaller than $\mathrm{Au} / \mathrm{TiO}_{2}$. This theoretical calculation does not take into account many parameters that have significant effects on the height of the barrier, such as presence of interface states, inhomogeneity, interface compounds, doping density etc. and defines the parameters in an ideal state. However, it is expected/founded to be compatible with the parameters obtained from the experiments. Therefore, it would be more appropriate to evaluate our diodes, which are 
prepared in identical form and built on the same substrate with the approach that they are consistent among themselves.

When this information was taken into consideration, the change in barrier heights depending on the $\phi_{m}$ were given in Figure 3. Here, the data related to $A u / n-G a A s$ SD not taken into consideration when evaluating the relationship between metal's $\phi_{m}$ and $\Phi_{b}$ values. The expected barrier height values could not be observed due to alloying behavior. This behavior causes the AuGa compounds to change the interface chemistry of the Au-GaAs interface as a result of some $\mathrm{Ga}$ out-diffusion and solid-state reactions with $\mathrm{Au}$, and the remaining As atoms make the semiconductor highly doped $[35,37,48]$. The exact alloying mechanism that causes the degradation of the SDs was not very clear. This will result in significant field emissions along the barrier and increase the flow through it [48].

This behavior also observed in studies on AlGaN or GaN substrates [29]. In this study, although there is no annealing process, Ga migration due to solid-state reactions also observed on the contact surface by EDX measurements.

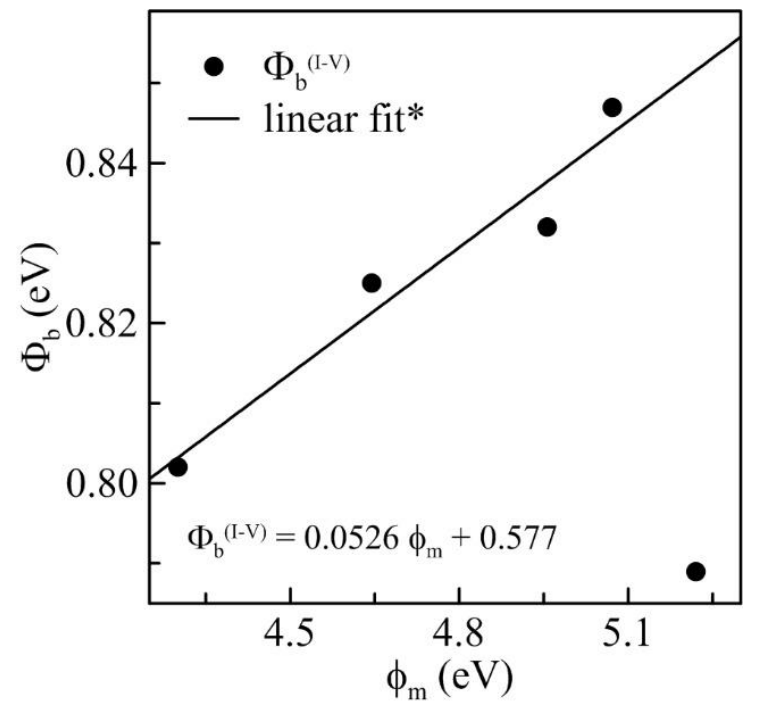

Figure 3. Least squares fit to the $A u-A g / n-G a A s$ SDs $\Phi_{b}{ }^{I V}$ and calculated $\phi_{m}$ data. $*$ The data of $A u / n-G a A s$ SDs not include fit range.

On the other hand, the presence of a small amount of Ag prevents this diffusion and prevents the gallide phases to occur at the interface $[30,31]$. There are many examples in the literature (especially in SD on ternary and quaternary semiconductor substrates) where a thin layer of metal barrier is used to prevent these diffusion/out-diffusion processes [49].

As mentioned earlier, the slope of linear fit in $\Phi_{b}$ versus $\phi_{m}$ graph was an indicator of Fermi level pinning and called as "interface behavior parameter" or "gap states parameter" (S) of the semiconductor [2,8]. Here, if $S=0$ state is called as a "Bardeen limit", if $S=1$ state is called "Schottky limit". S parameter was determined as 0.0526 and close to the Bardeen limit, in our study. Therefore, surface states or interface states stabilize the Fermi level of the metalsemiconductor system and, depending on the characteristic parameters of the metal, thus Fermi 
level remains unchanged. In this case, the relationship between the density of the interface states and the $\mathrm{S}$ parameter given as follow,

$$
S=\frac{d \Phi_{b}^{I V}}{d \phi_{m}}=\left(1+\frac{q^{2} \delta D_{i t}}{\varepsilon_{i}}\right)^{-1}
$$

where, $\varepsilon_{i}$ and $\delta$ are permittivity of the interfacial layer and thickness of interfacial layer, respectively [2,34]. Assuming the $\varepsilon_{i}=5 \varepsilon_{0}$ and $\delta=5 \AA$, we calculate $D_{i t}=1.801 \times 10^{11} \mathrm{eVcm}^{-2}$ from $S$ according to the Equation (5), which has a good agreement with the later results and literature [50].

The downward curvature in $I-V$ curves at relatively high forward bias voltage region arises from the series resistance $\left(R_{S}\right)$, of the semiconductor bulk between the depletion region and Ohmic contact. The $R_{s}$ values of $A u-A g / n-G a A s$ SD were calculated using two different methods developed by Cheung's [51] and Norde [52] obtained from the forward bias current equations (Equation 3-4). According to the Cheung and Cheung theory, the barrier height as well as other diode parameters such as $n$ and $R_{s}$ was also could be determined using Cheung's functions;

$$
d V / d \ln (I)=n k T / q+I R_{S}
$$

and

$$
H(I)=I R_{S}+n \Phi_{b}
$$

the y-axis intercept and slope of a plot of $d V / d(\ln I)$ vs. $I$ give $n q / k T$ and $R s$. Also, a plot of $H(I)$ vs. $I$ give a straight line with the y-axis intercept equal to $n \Phi_{b}{ }^{C h}$ (not plotted in here) The slope of this plots also provides a second determination of $R_{s}$, which can be used to check the consistency of Cheung's approach. The obtained $R_{s}, n$ and $\Phi_{b}{ }^{C h}$ of the SDs were given in Table 2. This serial resistance values were consistent with the literature $[46,53]$

Table 2 also contains Norde method results. According to the Norde's method, Norde function $(F(V))$ were expressed as in Equation (7) and where $I(V)$ and $\gamma$ was a bias dependent current value obtained from the $I-V$ plots and dimensionless integer larger than ideality factor $(\gamma>n)$, respectively,

and

$$
F(V)=V / \gamma-k T / q \ln \left(I(V) / A A^{*} T^{2}\right)
$$

$$
R_{S}=\frac{k T(\gamma-n)}{q I_{\min }}
$$

and also barrier height $\left(\Phi_{b}{ }^{N}\right)$ given by the

$$
\Phi_{b}^{N}=F\left(V_{\min }\right)+V_{\min } / 2+k T / q
$$

where $F\left(V_{\min }\right)$ was a minimum point value of $F(V), V_{\min }$ and $I_{\min }$ corresponding voltage and current values. The plots of $F(V)$ versus $V$ for the $A u-A g / n-G a A s$ SDs using. Mean values of $\Phi_{b}{ }^{N}$ and $R_{s}$ values of twenty $A u-A g / n-G a A s$ SD were summarized in Table 2. 
As can be seen from Table 2, mean $\Phi_{b}$ and $R_{s}$ values of SD for each set was found to be consistent with the Cheung's approach and Norde's method. $R_{s}$ values of an intimate metalsemiconductor contact without any desired interfacial layer must only arise from the bulk. The higher values of $R_{s}$ may be arise from the contribution of the native oxide layer on the semiconductor surface to the neutral region series resistance plus imperfect Ohmic contact. However, in the process of making Ohmic contacts and SD it has contributed to contact resistance in the alloys resulting from solid-state reactions [46].

Table 2. Mean characteristics diode parameters and standard deviations of the twenty (for each set) $\mathrm{Au}-\mathrm{Ag} / \mathrm{n}-\mathrm{GaAs}$ SDs obtained from Cheung functions and Norde plots.

\begin{tabular}{|c|c|c|c|c|c|c|c|}
\hline \multirow{2}{*}{$\begin{array}{c}\text { Schottky } \\
\text { metal }\end{array}$} & \multirow{2}{*}{$\begin{array}{c}\mathbf{I}_{0} \\
\left(\mathbf{x 1 0}^{-11} \mathrm{~A}\right)\end{array}$} & \multicolumn{4}{|c|}{ Cheung } & \multicolumn{2}{|c|}{ Norde } \\
\hline & & $n$ & $R_{S}(\Omega)$ & $\Phi_{b}{ }^{C h}(e V)$ & $R_{S}(\Omega)$ & $\Phi_{b}^{N}(e V)$ & $R_{S}(\Omega)$ \\
\hline $\mathbf{A u}$ & $41.27 \pm 19.30$ & $1.163 \pm 0.059$ & $31.33 \pm 10.34$ & $0.785 \pm 0.033$ & $31.24 \pm 10.47$ & $0.704 \pm 0.018$ & $29.66 \pm 10.66$ \\
\hline $\mathbf{A u}_{0.71} \mathbf{A g}_{0.29}$ & $3.670 \pm 1.306$ & $1.128 \pm 0.022$ & $14.02 \pm 4.35$ & $0.856 \pm 0.010$ & $13.81 \pm 4.23$ & $0.741 \pm 0.005$ & $13.61 \pm 3.46$ \\
\hline $\mathbf{A u}_{0.37} \mathbf{A g}_{0.63}$ & $6.412 \pm 1.078$ & $1.186 \pm 0.044$ & $36.28 \pm 11.77$ & $0.824 \pm 0.015$ & $36.08 \pm 12.04$ & $0.743 \pm 0.007$ & $33.31 \pm 12.27$ \\
\hline $\mathbf{A u}_{0.22} \mathbf{A g}_{0.78}$ & $8.776 \pm 3.947$ & $1.236 \pm 0.041$ & $9.37 \pm 4.59$ & $0.820 \pm 0.012$ & $8.92 \pm 4.69$ & $0.742 \pm 0.009$ & $9.33 \pm 3.98$ \\
\hline Ag & $20.68 \pm 4.573$ & $1.224 \pm 0.041$ & $4.37 \pm 2.66$ & $0.809 \pm 0.012$ & $3.87 \pm 2.66$ & $0.719 \pm 0.008$ & $5.98 \pm 1.65$ \\
\hline
\end{tabular}

If there are interface states exist between metal and semiconductor and in equilibrium with semiconductor, the ideality factor of the SD will be greater than unity because of this conditions $[16,54]$. The density of these states $\left(D_{i t}^{I V}\right)$ expressed as following equation;

$$
D_{i t}^{I V}=1 / q\left[\varepsilon_{i} / d(n(V)-1)-\varepsilon_{s} / w\right]
$$

Here, $d$ and $\varepsilon_{s}$ are the interfacial layer width and permittivity of the semiconductor, respectively. The depletion layer width was determined from the $C$ - $V$ measurements at a high frequency. Also, $n(V)$ is the ideality factor depending on the bias voltage and given by $n(V)=$ $(V / k T) \ln \left(I / I_{0}\right)$. In an n-type semiconductor, the energy of the interface states $E_{\mathrm{ss}}$ with respect to the top of the conduction band $\left(E_{c}\right)$ at the surface of the semiconductor is given by

$$
E_{c}-E_{s s}=q \phi_{e}-q V
$$

where, $\mathrm{q} \phi_{e}=\Phi_{b}^{I V}+(1-1 / n) q V$. Interface state density distribution profile of the s for $A u$ $A g / n-G a A s$ SDs were obtained from the experimental $I-V$ plots and were shown in Figure 4. For all $A u-A g / n-G a A s$ SDs there was a slight exponential increment seen in $D_{i t}^{I V}$ from the nearly mid-gap towards the bottom of the conductance band. Furthermore, when the Ag content increased in the Schottky contact metal, the interface state density increases. This decreasing $D_{i t}^{I V}$ values are supports our proposed approach for interface chemistry by a Ga out-diffusion. Gallide phases causes a much lower interface state density. 


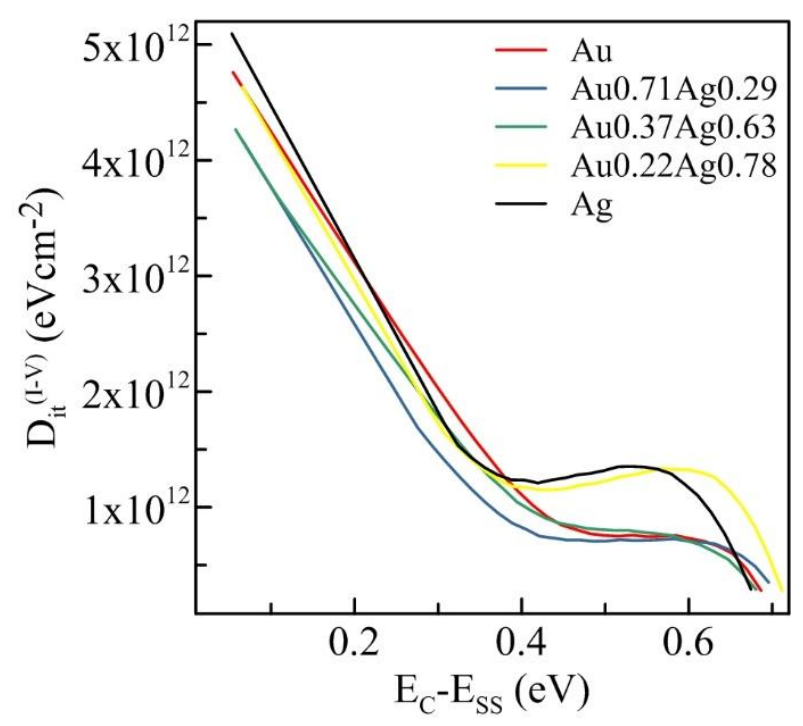

Figure 4. $D_{i t}^{I V}$ vs. $E_{C}-E_{S S}$ plots for $A u-A g / n-G a A s$ SDs.

\subsection{Reverse bias $I-V$ characteristics of the $A u-A g / n-G a A s$ SDs}

Reverse bias $I-V$ characteristics could also be used for determine some parameters of the fabricated $A u-A g / n-G a A s$ SDs. Figure 2 reveals that the reverse current $\left(I_{R}\right)$ of the $A u-A g / n$ GaAs SDs increases with increasing bias, but not saturated. Different mechanisms cause a leakage current and becomes an effective. The reverse current conduction mechanism of $\mathrm{Au}$ $A g / n-G a A s$ investigated based on the Poole-Frenkel emission (PFE) and Schottky emission (SE) models $[33,55]$. The reverse bias current as a function of the negative bias can be written as

$$
I_{R}=I_{0 R} \exp \left(\beta_{P F} V^{1 / 2} / k T d^{1 / 2}\right)
$$

here

$$
I_{0 R}=A A^{*} T^{2} \exp \left(-\Phi_{b}^{R B} / k T\right)
$$

where $I_{O R}, \beta_{P F}$ and $\Phi_{b}{ }^{R B}$ are reverse saturation current, PFE field-lowering coefficient and reverse bias barrier height $\left(\Phi_{b}{ }^{R B}\right)$, respectively. The theoretical values of field lowering coefficients given by

$$
\beta_{P F}^{*}=2 \beta_{S E}=\left[q^{3} / \pi \varepsilon_{S} \varepsilon_{0}\right]^{1 / 2}
$$

where $\beta_{S E}$ is the field-lowering coefficient of SE. According to Equation (11), the theoretical values of the field lowering coefficients $\left(\beta_{P F}{ }^{*}\right)$ for the $A u-A g / n-G a A s$ SDs were determined as $4.412 \times 10^{-5} \mathrm{eVm}^{1 / 2} \mathrm{~V}^{-1 / 2}$. Mean values of $\Phi_{b}{ }^{R B}$ and $\beta_{P F}$ values of twenty $A u-A g / n-G a A s$ SD were summarized for each set in Table 3. As can be seen from Table 3, values of experimental slope for the $A u-A g / n-G a A s$ SDs are changes from $1.375 \pm 0.068 \mathrm{eVm}^{1 / 2} \mathrm{~V}^{-1 / 2}$ to $1.560 \pm 0.209 \mathrm{eVm}^{1 / 2} \mathrm{~V}^{-1 / 2}$, which were closely matched with the theoretical slope of SE. Thus, the dominating charge conduction mechanism for the $A u-A g / n-G a A s$ SDs are assumed the SE. 
Table 3. Mean characteristics diode parameters and standard deviations of the twenty (for each set) $A u-A g / n-G a A s$ SDs obtained from reverse bias $I-V$ plots.

\begin{tabular}{|c|c|c|c|c|}
\hline $\begin{array}{l}\text { Schottky } \\
\text { metal }\end{array}$ & Model & $\begin{array}{c}\beta_{P F} \\
\left(x 10^{-5} \mathrm{eVm}^{1 / 2} \mathbf{V}^{-1 / 2}\right)\end{array}$ & $\begin{array}{l}\Phi_{b}^{R B} \\
(e V)\end{array}$ & $\begin{array}{c}I_{0} \\
\left(x 10^{-8} A\right)\end{array}$ \\
\hline $\mathbf{A u}$ & Schottky emission & $1.450 \pm 0.160$ & $0.671 \pm 0.022$ & $5.507 \pm 9.509$ \\
\hline $\mathrm{Au}_{0.71 \mathrm{Ag}_{0.29}}$ & Schottky emission & $1.502 \pm 0.122$ & $0.715 \pm 0.024$ & $0.939 \pm 1.036$ \\
\hline Au0.37Ag0.63 & Schottky emission & $1.540 \pm 0.198$ & $0.704 \pm 0.026$ & $1.305 \pm 0.888$ \\
\hline Au0.22Ag0.78 & Schottky emission & $1.375 \pm 0.068$ & $0.677 \pm 0.036$ & $6.832 \pm 10.02$ \\
\hline Ag & Schottky emission & $1.560 \pm 0.209$ & $0.711 \pm 0.040$ & $1.848 \pm 3.170$ \\
\hline
\end{tabular}

\section{4. $C-V$ characteristics of the $A u-A g / n-G a A s S D$}

The bias dependent $C$ - $V$ characteristics of the $A u-A g / n-G a A s$ SDs measured at dark and room temperature. Figure 5 shows a plot of $\mathrm{C}^{-2}$ as a function of bias voltage for the $\mathrm{Au}-\mathrm{Ag}$ alloy (at.\% $0-100$ ) on $\mathrm{n}-\mathrm{GaAs}$ SDs at sufficiently high frequency (1 $\mathrm{MHz}$ or above). The main purpose of these $C-V$ measurements were reveal the properties of the space charge region of SDs. The relationship between the capacitance of the space charge region and the applied dc bias in metalsemiconductor contacts given as follows [7, 12],

$$
1 / C^{2}=\frac{2\left(V_{b i}{ }^{k T} / q^{-V}\right)}{A^{2} q N_{d} \varepsilon_{S}}
$$

where, $V_{b i}$ was the built-in potential and $N_{d}$ were the doping concentration of the GaAs substrate. According to the Equation (12) $\left(1 / C^{2}\right)$ versus $V$ plots gives straight line with the slope were equals to $2 / q \varepsilon_{s} N_{d}$ and intercepts the x-axis equals to $V_{0}$ (Figure 5). Here; $V_{0}$ is related with the built-in potential $V_{b i}$ by the equation $V_{b i}=V_{0}+k T / q$ and barrier height were given by equation [7],

$$
\Phi_{b}^{C V}=V_{b i}+V_{n}
$$

where, $V_{n}$ is the potential difference between the bottom of the conduction band and the Fermi level in the neutral region of n-GaAs and $V_{n}=(k T / q) \ln \left(N_{d} / N_{d}\right)$, where $N_{c}$ is the temperature dependent density of states in the conduction band and its value was calculated from the $N_{c}=2\left(2 \pi m^{*} / k T / h^{2}\right)^{3 / 2}$, and $\mathrm{m}^{*}=0.063 \mathrm{~m}_{0}$, and found $4.573 \times 10^{17} \mathrm{~cm}^{-3}$ for GaAs at $300 \mathrm{~K}$. The values of $\Phi_{b}{ }^{C V}$ and $N_{d}$ for the $A u-A g / n-G a A s$ SDs were given in Table 4. In Table 4, the barrier heights obtained by $C-V$ method of the SDs were changes between the $1.035 \pm 0.022 \mathrm{eV}$ and $0.912 \pm 0.013 \mathrm{eV}$. These obtained barrier height values are higher than obtained from $I-V$ measurements for corresponding to each alloy composition. Arulkumaran et al. prepared $A u / n$ GaAs and $A g / n-G a A s$ SDs and barrier height values varied from 0.82-0.93 eV and from 0.75$1.05 \mathrm{eV}$, respectively [44]. Also, barrier height found here were reasonable agreement with a value of $0.97 \mathrm{eV}$ from $C-V$ characteristics of $A u / n-G a A s$ and $A g / n-G a A s$ of nearly the same doping concentration [15]. 


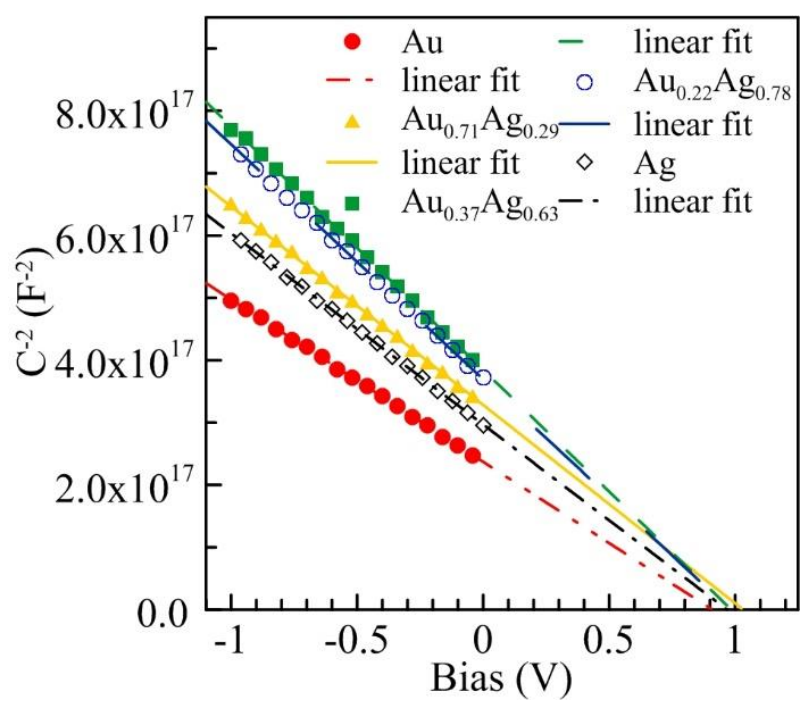

Figure 5. The $\mathrm{C}^{-2}$ versus reverse bias characteristics for the $A u-A g / n-G a A s$ SDs. Only one plot shown here for each set, representing the best value for the average results obtained from the measurements.

Although the same parameter was measured, the difference between the $\Phi_{b}{ }^{C V}$ 's can be attributed to existence of lateral inhomogeneity [56]. The source of this lateral inhomogeneity was potential fluctuations at the interface. These fluctuations generally attributed to the thickness of the contact metal, non-uniform distribution at the interface, dislocations, packing errors in the crystal and a thin native oxide layer at the interface, irregularities in the atomic scale on the semiconductor surface, and defects in bulk, and so on [56, 57]. These potential fluctuations affect the dc current and the capacitance measurements in different ways. Diode capacitance was caused by the displacement of the charge carriers in the space charge region due to the ac frequency signal. This displacement was observed at near the boundaries of the space charge region. Therefore, the capacitance of the diodes depends on this space charge region and causes the barrier height to be measured only as an average value. The dc current flowing through the diode preferably tends to flow only where the $\Phi_{b}{ }^{C V}$ was the lowest.

Table 4. The obtained characteristics diode parameters and standard deviations of the $A u-A g / n$ $G a A s$ SDs from the $C$ - $V$ measurements.

\begin{tabular}{|c|c|c|c|}
\hline Schottky metal & $\begin{array}{c}\mathrm{N}_{\mathrm{d}} \\
\left(\times \mathbf{x 1 0}^{17} \mathrm{~cm}^{-3}\right)\end{array}$ & $\begin{array}{l}\mathbf{V}_{\mathbf{b i}} \\
(\mathrm{V})\end{array}$ & $\begin{array}{l}\Phi_{b}^{C V} \\
(\mathrm{eV})\end{array}$ \\
\hline $\mathbf{A u}$ & $9.103 \pm 0.836$ & $0.909 \pm 0.012$ & $0.912 \pm 0.013$ \\
\hline Au0.71Ag0.29 & $8.288 \pm 0.789$ & $1.032 \pm 0.022$ & $1.035 \pm 0.022$ \\
\hline $\mathrm{Au}_{0.37} \mathrm{Ag}_{0.63}$ & $6.939 \pm 0.413$ & $0.998 \pm 0.025$ & $1.001 \pm 0.025$ \\
\hline Au0.22Ag0.78 & $6.886 \pm 0.672$ & $0.976 \pm 0.007$ & $0.980 \pm 0.007$ \\
\hline Ag & $8.097 \pm 1.235$ & $0.959 \pm 0.013$ & $0.963 \pm 0.013$ \\
\hline
\end{tabular}

Besides the $I-V$ measurements, the using a single-frequency approximation method [58] on the conductance measurements results, allows the estimation of the $D_{i t}$. This method was one of the reliable way to determine the density of interface states. According to this method, $D_{i t}{ }^{C V}$ can be find using the following formula, 


$$
D_{i t}^{C V}=\frac{2}{q A} \frac{\left(G_{m}\right)_{\max } / \omega}{\left(\left(G_{m}\right)_{\max } / \omega C_{o x}\right)^{2}+\left(1-{ }^{C} / C_{o x}\right)^{2}}
$$

where $G_{m} \omega$ are measured conductance and angular frequency of ac signal, $C_{m}$ is measured capacitance. $C_{\text {ox }}$ is the capacitance of oxide layer in accumulation region of $C$ - $V$ curves, $\left(G_{m}\right)_{\max }$ conforms to maximum $G-V$ curve and $C_{\mathrm{m}}$ is the capacitance of the diodes corresponding to $\left(G_{m}\right)_{\max }$. Also, the series resistance of the equivalent circuit is $[58,59]$,

$$
R_{s}=\frac{G_{m}}{G_{m}^{2}+w^{2} C_{m}^{2}}
$$

This method was applied on $C-V$ and $G-V$ measurement results in the frequency range from $200 \mathrm{~Hz}$ to $2 \mathrm{MHz}$ Figure 6 depicts the changings in $D_{i t}{ }^{C V}$ with the frequency, both axis is $\log$ scale. $D_{i t}{ }^{C V}$ values of $A u-A g / n-G a A s$ SDs strongly depend on frequencies and decrease at lower and higher frequency range. This " $U$ " type behavior of the interface states has a minimum value that varies from diode to diode.

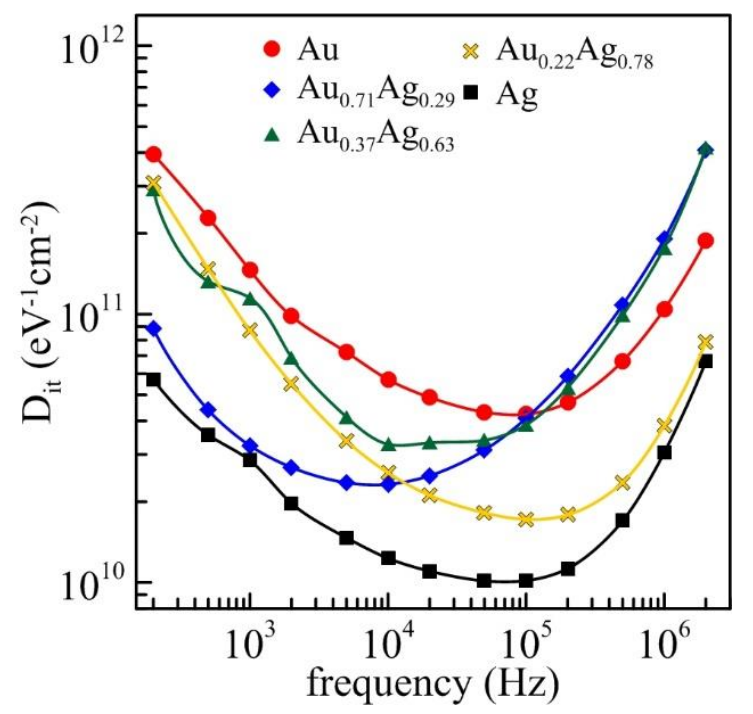

Figure 6. Mean $D_{i t}{ }^{C V}$ values versus ac signal frequency plots of the $A u-A g / n-G a A s$ SDs.

This minimum value and sufficiently constant $D_{i t}{ }^{C V}$ values appear at relatively high frequencies attributed to the excess capacitance. This excess capacitance because of interface states which is in equilibrium with the semiconductor that can easily follow the ac signal [60]. $D_{\mathrm{it}}{ }^{\mathrm{CV}}$ values of $A u-A g / n-G a A s$ SDs are same order as those reported by some authors. [50]. 


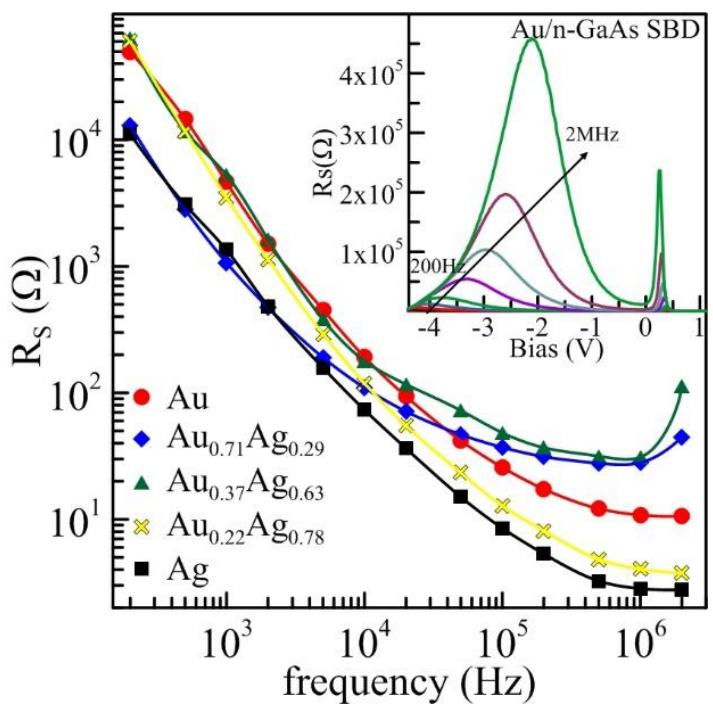

Figure 7. Mean $R_{S}$ values versus frequency plots of the $A u-A g / n-G a A s$ SDs. Inset shows bias dependent $R_{S}$ values of one of the $A u / n-G a A s$ SD.

The frequency dependent series resistance values of $A u-A g / n-G a A s$ SDs estimated according to Equation (15) using with the measured capacitance and conductance values in the frequency range from $200 \mathrm{~Hz}$ to $2 \mathrm{MHz}$ at room temperature and plotted in Figure 7 . This plot clearly indicates that when the frequency decreased, interface states cannot follow the ac signal and each states produces an excess capacitance and conductance, and becomes a resistive point for charge carriers and increases exponentially. Inset in Figure 7 shows that series resistance gives a peak depending on frequency in the wide negative bias range and second peak appear after $0 \mathrm{~V}$.

\section{Conclusion}

In this study, $A u-A g / n-G a A s$ SDs fabricated by thermal evaporation method and investigated the effect of work function of metals on SD's parameters. TLM results indicates that Ohmic contact resistance was very low and $E D X$ results indicates that the alloy's percentage (x) by weight values were $0.22,0.37$ and 0.71 . Also, $A F M$ images showed that the smooth contacts were made. $\operatorname{Au}_{\mathrm{x}} \operatorname{Ag}_{1-\mathrm{x}}(\mathrm{x}=0,0.22,0.37,0.71$ and 1$)$ alloys were used for fabricating SDs by following same cleaning procedure with using the n-type GaAs substrate and then, characterized by various methods and techniques. In addition, characteristic parameters of SDs have been determined and compared with each other.

The lowest mean barrier height of about $0.789 \pm 0.022 \mathrm{eV}$ in $A u / n-G a A s$ SDs and the highest mean barrier height $0.847 \pm 0.008 \mathrm{eV}$ in $A u_{0.71} \mathrm{Ag}_{0.29} / \mathrm{n}-\mathrm{GaAs}$ SDs were observed (from $\mathrm{I}-\mathrm{V}$ measurements). $\Phi_{b}$ values of $A u / n-G a A s$ SDs were lower than the expected value and, explained by the presence of the gallide phases at the interface. It was observed that the Ag was prevents the Au diffusion in to the GaAs substrate or out diffusion of Ga. Furthermore, it was found that an almost linear relationship between Schottky barrier height and metal work function (with $\left.\Phi_{b}^{I V}=0.0526 \phi_{m}+0.577\right)$. Gap states parameter $(S)$ found as a 0.0526 and, close to the Bardeen limit $(S=0)$. In summary, Fermi level pinning model proposed by Cowley and Sze applies not only to metal-GaAs contacts but also to alloy-GaAs contacts, and indicates that 
Fermi level was strongly pinned $0.577 \mathrm{eV}$ below the conduction band in our SD's. Also, from this dependency, the density of states was determined as $1.801 \times 10^{11} \mathrm{eVcm}^{-2}$. This interface state density value was in the same order of magnitude with the $D_{i t}{ }^{I V}$ values (calculated from $I-V$ measurement result) and $D_{i t}{ }^{C V}$ values (calculated from $C$ - $V$ measurement result).

\section{REFERENCES}

[1] J. Bardeen, Surface states and rectification at a metal semi-conductor contact, Physical Review, 71 (1947) 717.

[2] A. Cowley, S. Sze, Surface states and barrier height of metal-semiconductor systems, J Appl Phys, 36 (1965) 3212-3220.

[3] W. Schottky, On the Semiconductor Theory of Blocking and Point Contact Rectifiers (in German), Zeitschrift Fur Physik, 113 (1939) 367-414.

[4] W. Spitzer, C. Mead, Barrier Height Studies on Metal-Semiconductor Systems, J Appl Phys, 34 (1963) 3061-3069.

[5] W. Schottky, Semiconductor Theory of the Blocking Layer (in German),

Naturwissenschaften, 26 (1938) 843.

[6] N. Mott, Note on the contact between a metal and an insulator or semiconductor, in: Proc. Cambr. Philos. Soc, Cambridge Univ Press, 1938, pp. 568-572.

[7] E.H. Rhoderick, R.H. Williams, Metal-Semiconductor Contacts, Clarendon Press Oxford, 1988.

[8] R.T. Tung, The physics and chemistry of the Schottky barrier height, Applied Physics Reviews, 1 (2014) 011304.

[9] G. Myburg, F.D. Auret, W.E. Meyer, C.W. Louw, M.J. van Staden, Summary of Schottky barrier height data on epitaxially grown n- and p-GaAs, Thin Solid Films, 325 (1998) 181186.

[10] S.G. Louie, J.R. Chelikowsky, M.L. Cohen, Ionicity and the theory of Schottky barriers, Phys Rev B, 15 (1977) 2154-2162.

[11] R.T. Tung, Formation of an electric dipole at metal-semiconductor interfaces, Phys Rev B, 64 (2001) 205310.

[12] S.M. Sze, K.K. Ng, Metal-Semiconductor Contacts, in: Environ Sci Eng, John Wiley \& Sons, Inc., New Jersey, 2006, pp. 832.

[13] E. Bucher, S. Schulz, M.C. Lux-Steiner, P. Munz, U. Gubler, F. Greuter, Work function and barrier heights of transition metal silicides, Applied Physics A, 40 (1986) 71-77.

[14] J. Hu, K.C. Saraswat, H.S.P. Wong, Metal/III-V Schottky barrier height tuning for the design of nonalloyed III-V field-effect transistor source/drain contacts, J Appl Phys, 107 (2010).

[15] N. Newman, M. Vanschilfgaarde, T. Kendelwicz, M.D. Williams, W.E. Spicer, Electrical Study of Schottky Barriers on Atomically Clean GaAs(110) Surfaces, Phys Rev B, 33 (1986) 1146-1159.

[16] K. Maeda, H. Ikoma, K. Sato, T. Ishida, Current-Voltage Characteristics and Interface State Density of GaAs Schottky-Barrier, Appl Phys Lett, 62 (1993) 2560-2562.

[17] A. TÜRÜT, On current-voltage and capacitance-voltage characteristics of metalsemiconductor contacts, Turkish Journal of Physics, 44 (2020) 302-347.

[18] H. Hasegawa, H. Ohno, Unified disorder induced gap state model for insulatorsemiconductor and metal-semiconductor interfaces, Journal of Vacuum Science \& Technology B: Microelectronics Processing and Phenomena, 4 (1986) 1130-1138. 
[19] D. Tsukamoto, A. Shiro, Y. Shiraishi, Y. Sugano, S. Ichikawa, S. Tanaka, T. Hirai, Photocatalytic $\mathrm{H} 2 \mathrm{O} 2$ production from ethanol/O2 system using $\mathrm{TiO} 2$ loaded with $\mathrm{Au}-\mathrm{Ag}$ bimetallic alloy nanoparticles, Acs Catal, 2 (2012) 599-603.

[20] S. Küp, A. Taşer, İ. Kanmaz, B. Güzeldir, M. Sağlam, Effects of Au-Ag and Au-Cu alloy ratios on the temperature dependent current-voltage characteristics of $\mathrm{Au}-\mathrm{Ag} / \mathrm{n}-\mathrm{GaAs} / \mathrm{In}$ and Au-Cu/n-GaAs/In Schottky diodes, Materials Today: Proceedings, 18 (2019) 1936-1945. [21] G.K. Reeves, H.B. Harrison, Obtaining the Specific Contact Resistance from Transmission-Line Model Measurements, Electron Devic Lett, 3 (1982) 111-113. [22] A. Akkaya, E. Ayy1ldız, Automation Software for Semiconductor Research Laboratories: Electrical Parameter Calculation Program (SeCLaS-PC), Journal of Circuits, Systems and Computers, 29 (2020) 2050215.

[23] A. Akkaya, E. Ayyıldız, Automation Software for Semiconductor Research Laboratories: Measurement System and Instrument Control Program (SeCLaS-IC), MAPAN, 35 (2020) 343-350.

[24] S. Fain Jr, J. McDavid, Work-function variation with alloy composition: Ag-Au, Phys Rev B, 9 (1974) 5099.

[25] R. Ishii, K. Matsumura, A. Sakai, T. Sakata, Work function of binary alloys, Appl Surf Sci, 169-170 (2001) 658-661.

[26] C. Kittel, Introduction to Solid State Physics, Wiley, USA, 1996.

[27] H.I. Chen, C.K. Hsiung, Y.I. Chou, Characterization of Pd-GaAs Schottky diodes prepared by the electroless plating technique, Semicond Sci Tech, 18 (2003) 620-626.

[28] A. Turut, D.E. Yıldız, A. Karabulut, İ. Orak, Electrical characteristics of atomic layer deposited $\mathrm{Au} / \mathrm{Ti} / \mathrm{HfO} 2 / \mathrm{n}-\mathrm{GaAs}$ MIS diodes in the wide temperature range, Journal of Materials Science: Materials in Electronics, 31 (2020) 7839-7849.

[29] A. Akkaya, L. Esmer, B.B. Kantar, H. Çetin, E. Ayyıldız, Effect of thermal annealing on electrical and structural properties of $\mathrm{Ni} / \mathrm{Au} / \mathrm{n}-\mathrm{GaN}$ Schottky contacts, Microelectron Eng, 130 (2014) 62-68.

[30] J. Ahopelto, V.M. Airaksinen, E. Siren, H.M. Niemi, Fabrication of sub-100 nm GaAs columns by reactive ion etching using Au islands as etching mask, Journal of Vacuum

Science \& Technology B: Microelectronics and Nanometer Structures Processing, Measurement, and Phenomena, 13 (1995) 161-162.

[31] V.G. Weizer, N.S. Fatemi, The interaction of gold with gallium arsenide, J Appl Phys, 64 (1988) 4618-4623.

[32] C. Messmer, J.C. Bilello, The surface energy of Si, GaAs, and GaP, J Appl Phys, 52 (1981) 4623-4629.

[33] S. Sze, Physics of Semiconductor Devices, John Wiley \& Sons, New York, 1981.

[34] L. Huang, R. Geiod, D. Wang, Barrier inhomogeneities and interface states of metal/4H-

SiC Schottky contacts, Jpn J Appl Phys, 55 (2016) 124101.

[35] A.K. Sinha, J.M. Poate, Effect of alloying behavior on the electrical characteristics of nGaAs Schottky diodes metallized with W, Au, and Pt, Appl Phys Lett, 23 (1973) 666-668.

[36] J. Gyulai, J. Mayer, V. Rodriguez, A. Yu, H. Gopen, Alloying Behavior of Au and AuGe on GaAs, J Appl Phys, 42 (1971) 3578-3585.

[37] C.J. Madams, D.V. Morgan, M.J. Howes, OUTMIGRATION OF GALLIUM FROM Au-GaAs INTERFACES, Electron Lett, 11 (1975) 574-575.

[38] D. Eastman, Photoelectric work functions of transition, rare-earth, and noble metals, Phys Rev B, 2 (1970) 1.

[39] M. Soylu, F. Yakuphanoglu, Analysis of barrier height inhomogeneity in Au/n-GaAs Schottky barrier diodes by Tung model, J Alloy Compd, 506 (2010) 418-422. 
[40] H. Altuntas, S. Altındal, S. Özçelik, H. Shtrikman, Electrical characteristics of Au/nGaAs Schottky barrier diodes with and without $\mathrm{SiO} 2$ insulator layer at room temperature, Vacuum, 83 (2009) 1060-1065.

[41] S. Tunhuma, F. Auret, M. Legodi, M. Diale, The effect of high temperatures on the electrical characteristics of Au/n-GaAs Schottky diodes, Physica B: Condensed Matter, 480 (2016) 201-205.

[42] A.F. Ozdemir, A. Türüt, A. Kokce, The double Gaussian distribution of barrier heights in Au/n-GaAs Schottky diodes from I-V-T characteristics, Semicond Sci Tech, 21 (2006) 298302.

[43] D. Korucu, A. Turut, H. Efeoglu, Temperature dependent I-V characteristics of an Au/nGaAs Schottky diode analyzed using Tung's model, Physica B, 414 (2013) 35-41.

[44] S. Arulkumaran, J. Arokiaraj, M. Udhayasankar, P. Santhanaraghavan, J. Kumar, P. Ramasamy, Investigations on $\mathrm{Au}, \mathrm{Ag}$, and Al Schottky Diodes on Liquid Encapsulated Czochralski-Grown N-GaAs[100], J Electron Mater, 24 (1995) 813-817.

[45] J.R. Waldrop, Influence of S and Se on the Schottky-Barrier Height and Interface Chemistry of Au Contacts to GaAs, J Vac Sci Technol B, 3 (1985) 1197-1201.

[46] O. Kahveci, A. Akkaya, E. Ayyıldız, A. Türüt, Comparison of yhe Ti/N-GaAs Schottky Contacts' Parameters Fabricated Using dc Magnetron Sputtering and Thermal Evaporation, Surf Rev Lett, 24 (2016) 1750047.

[47] S.W. Pang, G.A. Lincoln, R.W. McClelland, P.D. DeGraff, M.W. Geis, W.J. Piacentini, Effects of dry etching on GaAs, Journal of Vacuum Science \& Technology B:

Microelectronics Processing and Phenomena, 1 (1983) 1334-1337.

[48] S. Guha, B.M. Arora, V.P. Salvi, High temperature annealing behaviour of Schottky barriers on GaAs with gold and gold-gallium contacts, Solid State Electronics, 20 (1977) 431432,IN431-IN432.

[49] T. Nishimura, K. Kita, A. Toriumi, A significant shift of Schottky barrier heights at strongly pinned metal/germanium interface by inserting an ultra-thin insulating film, Appl Phys Express, 1 (2008).

[50] M. Ambrico, M. Losurdo, P. Capezzuto, G. Bruno, T. Ligonzo, L. Schiavulli, I. Farella, V. Augelli, A study of remote plasma nitrided nGaAs/Au Schottky barrier, Solid State Electron, 49 (2005) 413-419.

[51] S.K. Cheung, N.W. Cheung, Extraction of Schottky Diode Parameters from Forward Current-Voltage Characteristics, Appl Phys Lett, 49 (1986) 85-87.

[52] H. Norde, A modified forward I-V plot for Schottky diodes with high series resistance, J Appl Phys, 50 (1979) 5052-5053.

[53] P. Jayavel, J. Kumar, P. Ramasamy, R. Premanand, On the evaluation of Schottky barrier diode parameters of Pd, Au and Ag/n-GaAs, Indian J Eng Mater S, 7 (2000) 340-343.

[54] A. Singh, Characterization of Interface States at Ni/Ncdf2 Schottky-Barrier Type Diodes and the Effect of Cdf2 Surface Preparation, Solid State Electron, 28 (1985) 223-232.

[55] V.R. Reddy, Electrical properties of Au/polyvinylidene fluoride/n-InP Schottky diode with polymer interlayer, Thin Solid Films, 556 (2014) 300-306.

[56] J.H. Werner, H.H. Güttler, Transport properties of inhomogeneous Schottky contacts, Phys Scripta, 1991 (2007) 258.

[57] R.T. Tung, Recent advances in Schottky barrier concepts, Mat Sci Eng R, 35 (2001) 1138.

[58] W.A. Hill, C.C. Coleman, A Single-Frequency Approximation for Interface-State

Density Determination, Solid State Electron, 23 (1980) 987-993.

[59] E.H. Nicollian, J.R. Brews, Mos (Metal Oxide Semiconductor) Physics And Technology, Wiley-Interscience, New York, 1982. 
[60] D. Korucu, S. Altındal, T.S. Mammadov, S. Özçelik, The frequency dependent electrical characteristics of Sn/p-InP Schottky barrier diodes (SBDs), Optoelectron Adv Mat, 2 (2008) 525-529. 


\section{Figures}
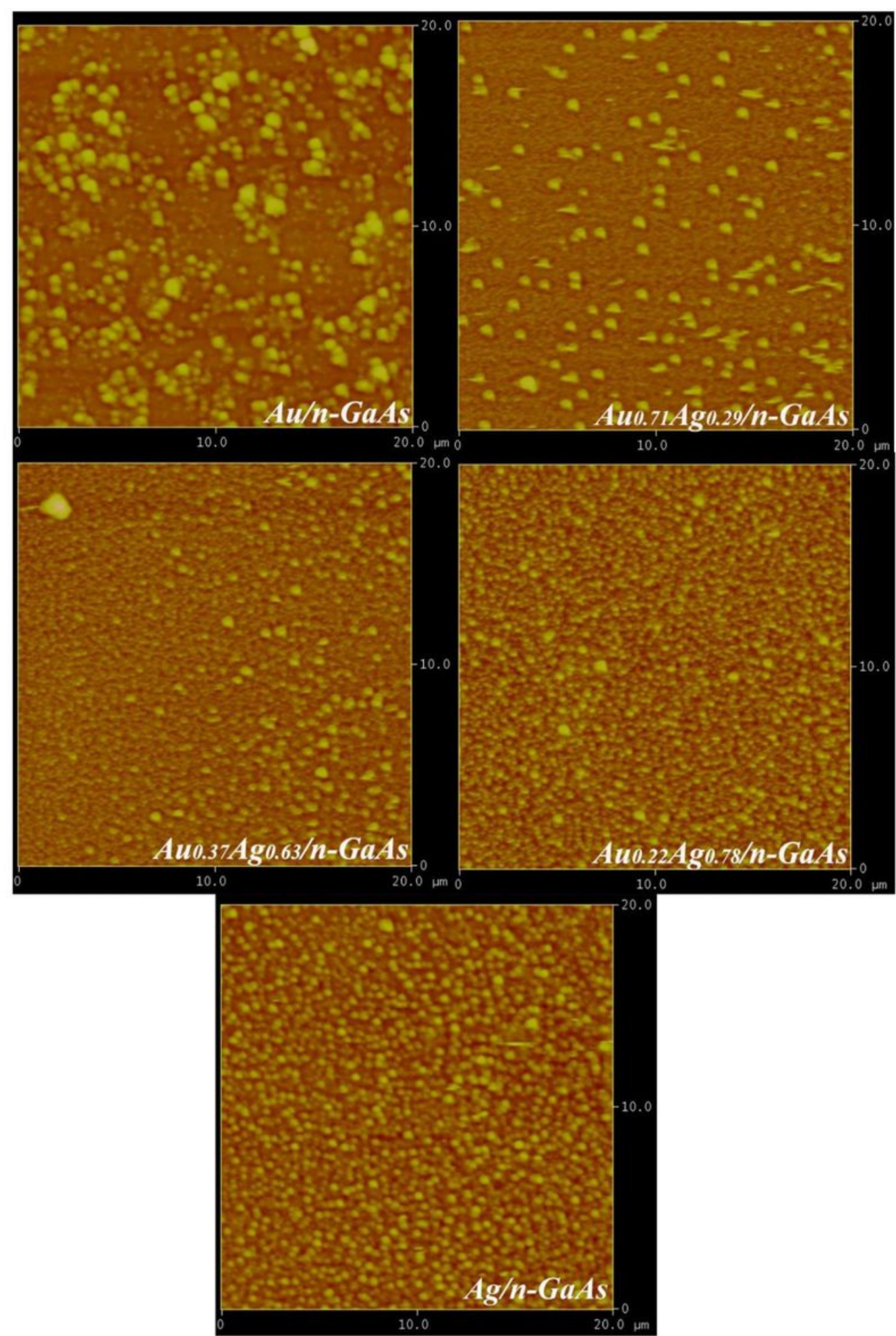

Figure 1

AFM micrographs of the Au-Ag Schottky contacts to n-type GaAs. 


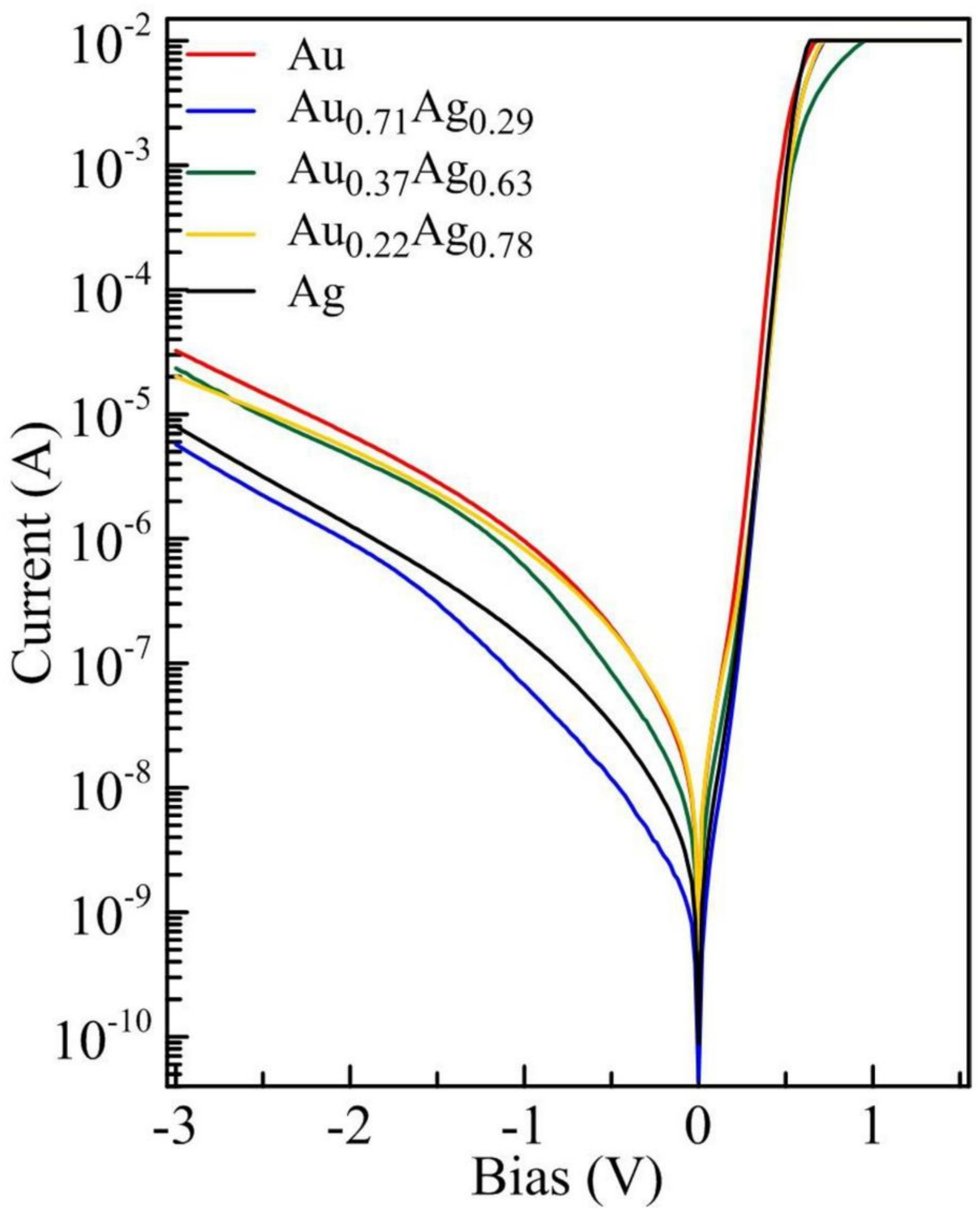

Figure 2

The semi-logarithmic I-V characteristics for the Au-Ag/n-GaAs SDs. Only one plot shown here for each set, representing the best value for the average results obtained from the measurements. 


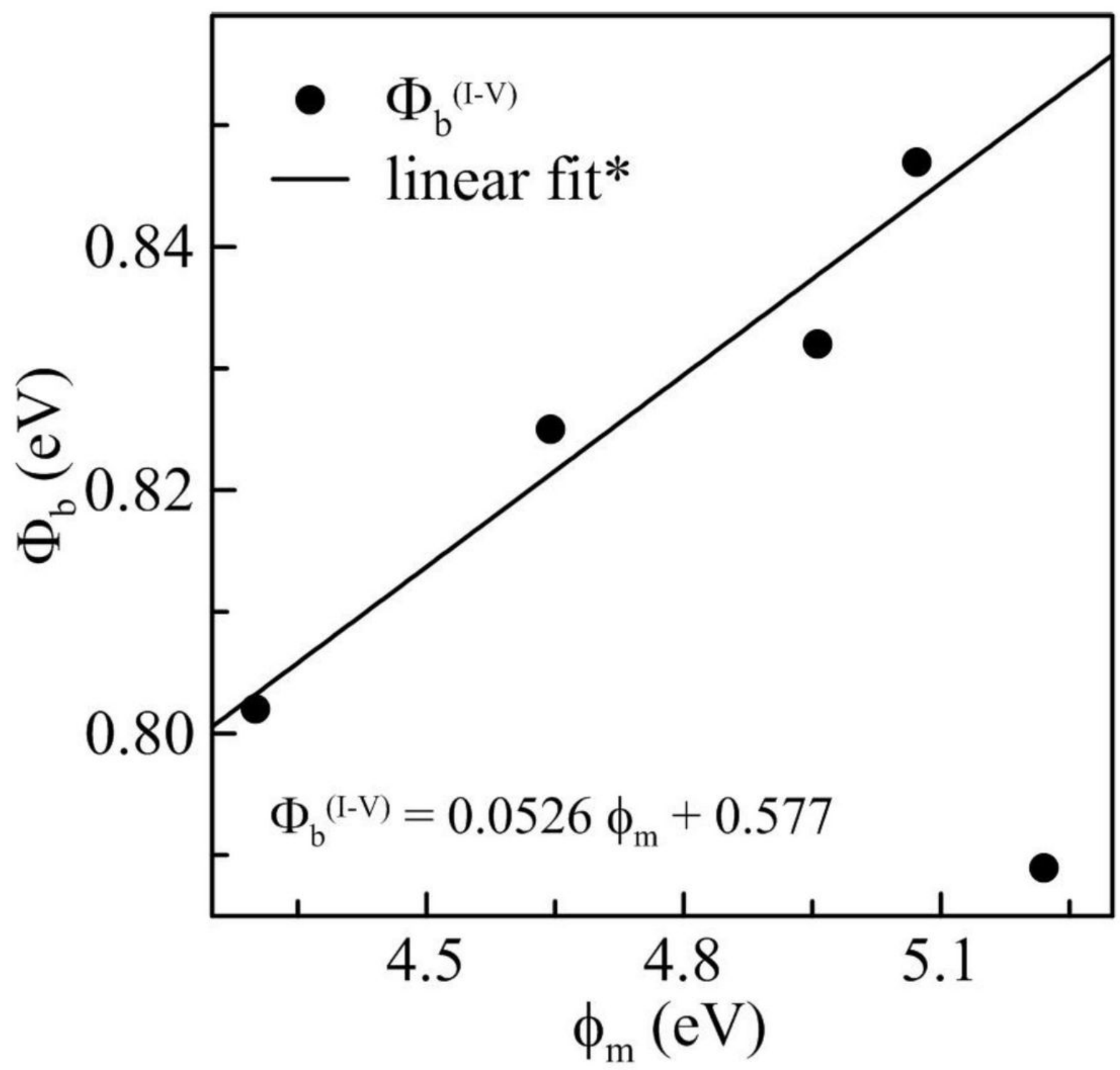

Figure 3

Least squares fit to the Au-Ag/n-GaAs SDs $\Phi$ bIV and calculated $\nabla_{-} m$ data. * The data of $\mathrm{Au} / \mathrm{n}-\mathrm{GaAs} \mathrm{SDs}$ not include fit range. 


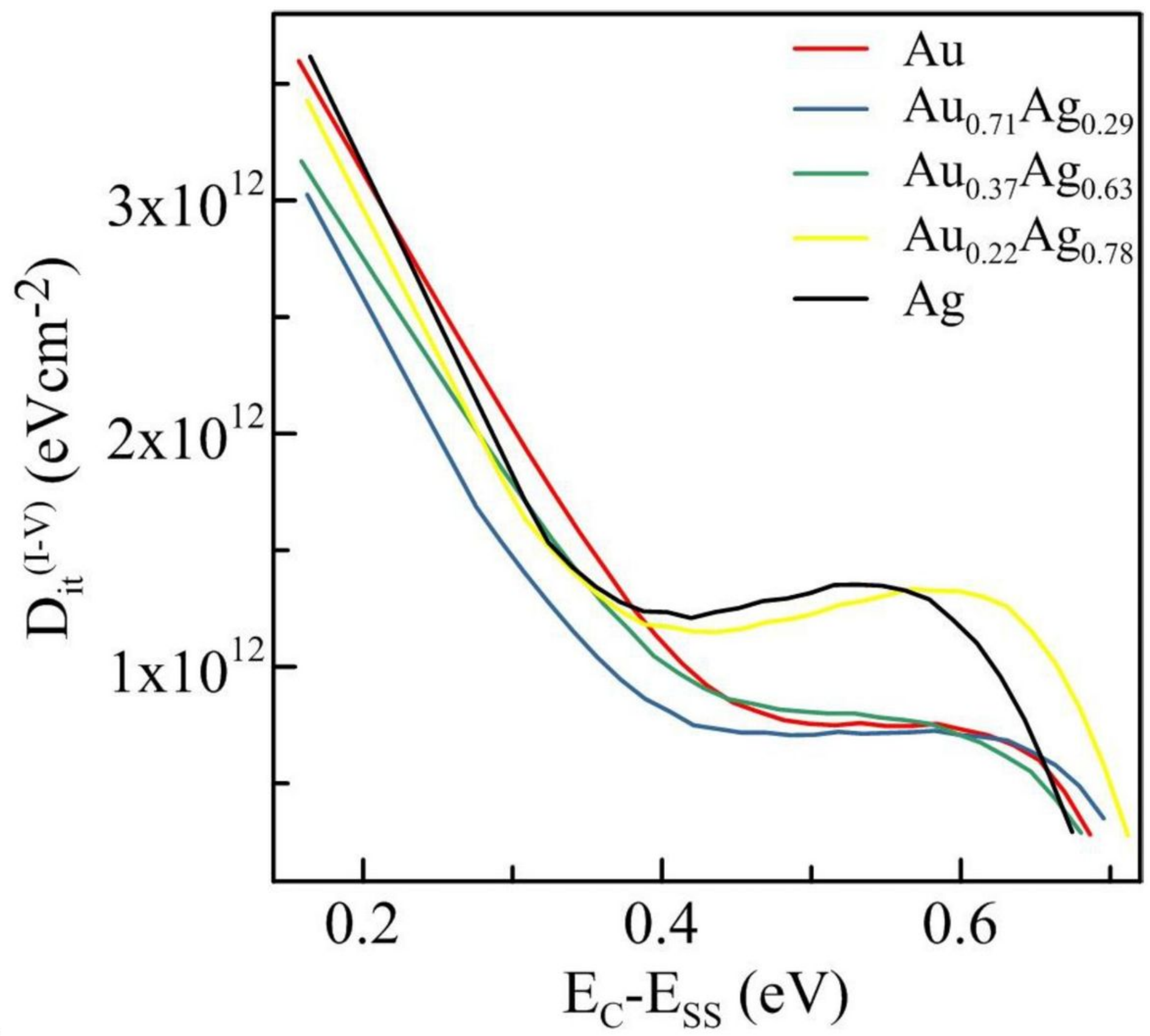

Figure 4

Please see the Manuscript PDF file for the complete figure caption 


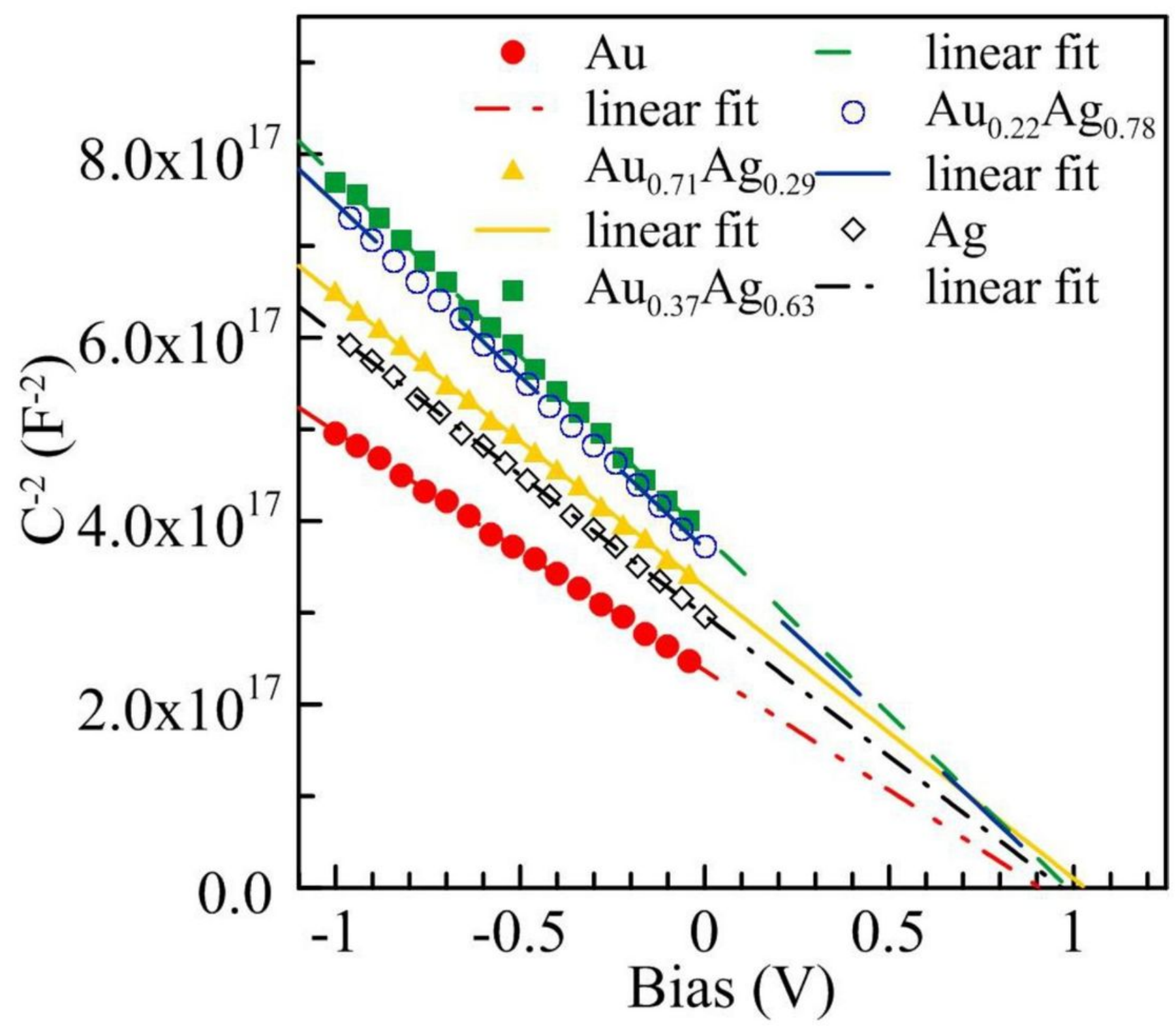

Figure 5

The $\mathrm{C}-2$ versus reverse bias characteristics for the Au-Ag/n-GaAs SDs. Only one plot shown here for each set, representing the best value for the average results obtained from the measurements. 


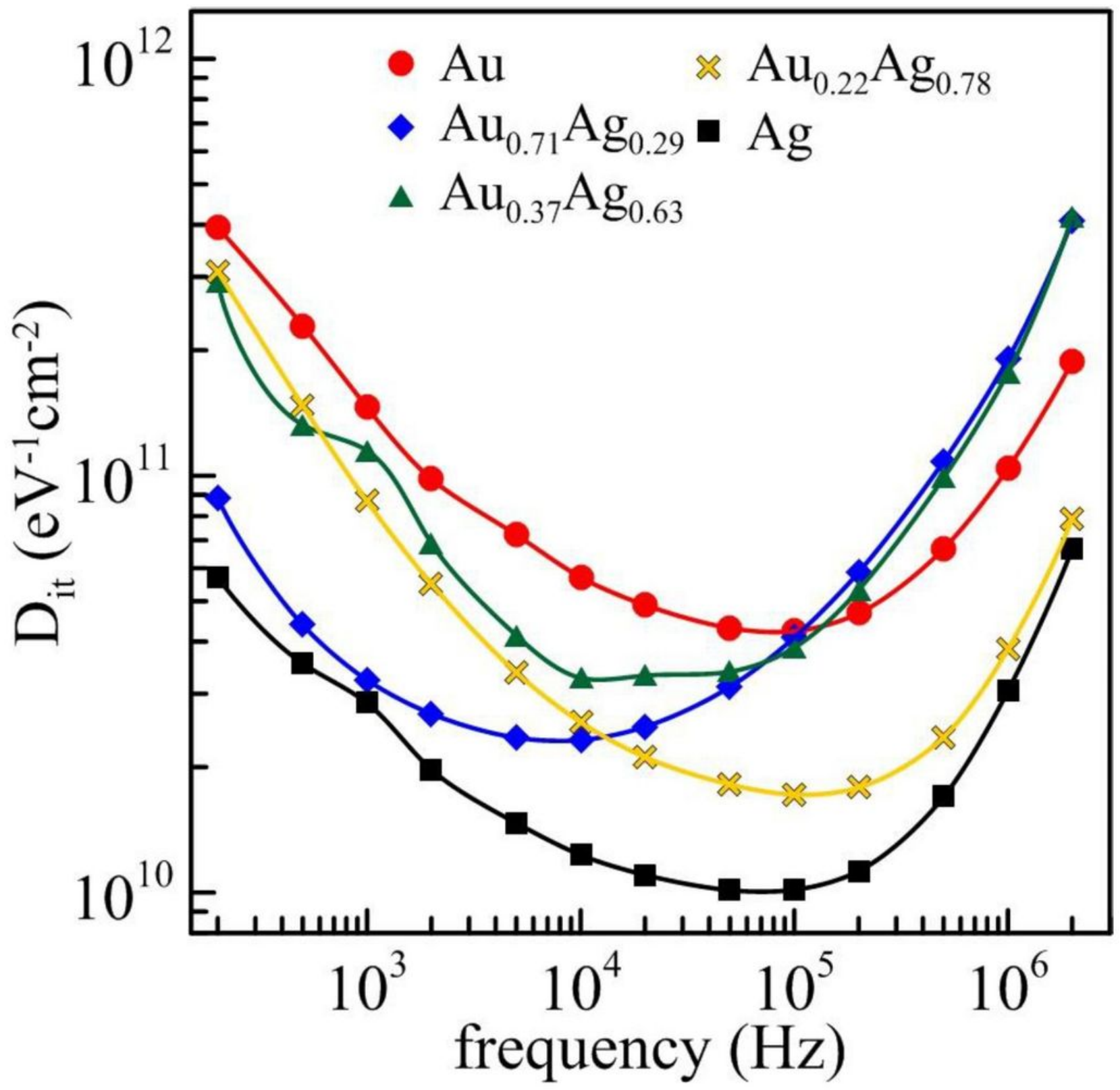

Figure 6

Please see the Manuscript PDF file for the complete figure caption 


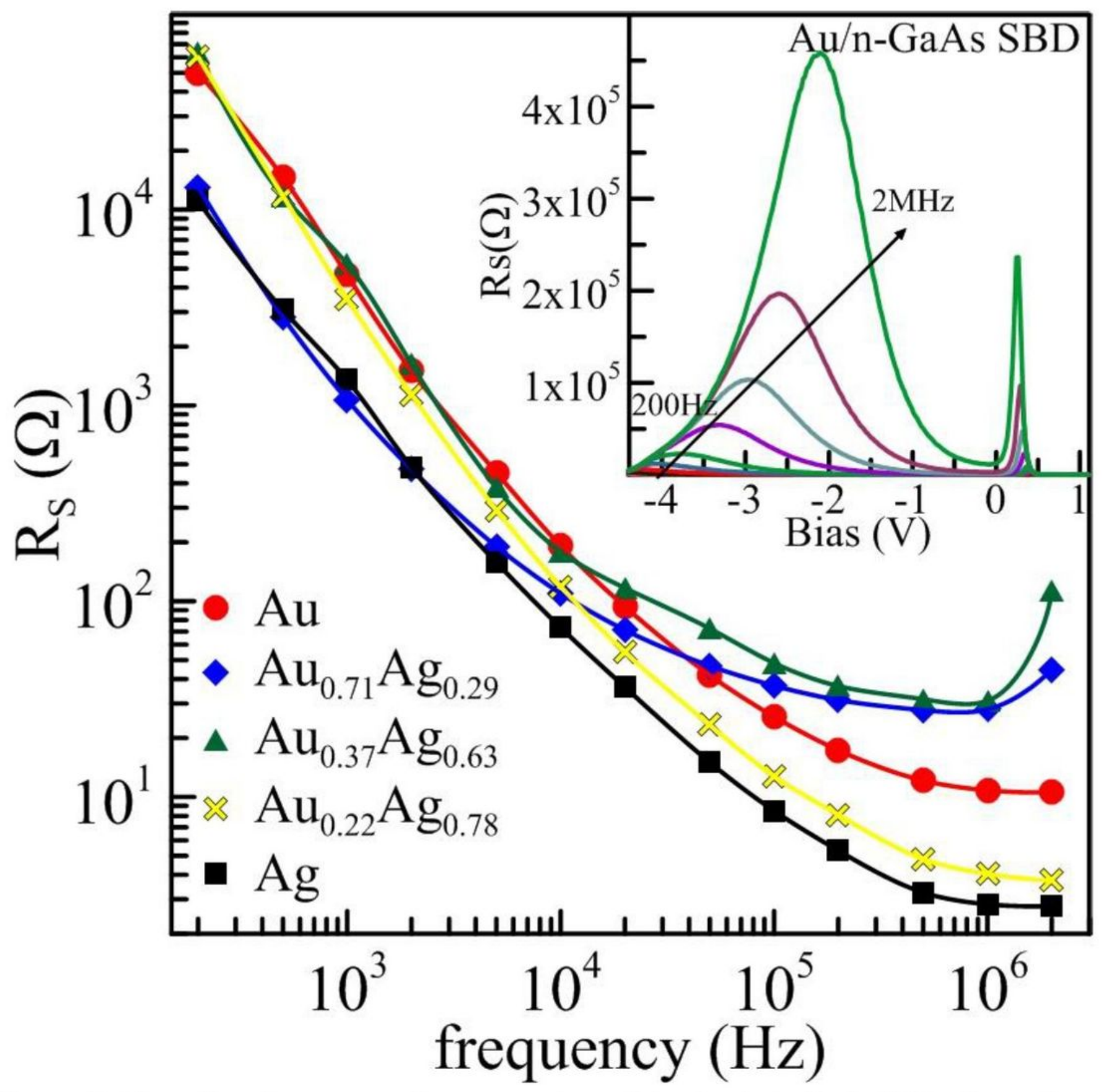

Figure 7

Mean RS values versus frequency plots of the Au-Ag/n-GaAs SDs. Inset shows bias dependent RS values of one of the Au/n-GaAs SD. 